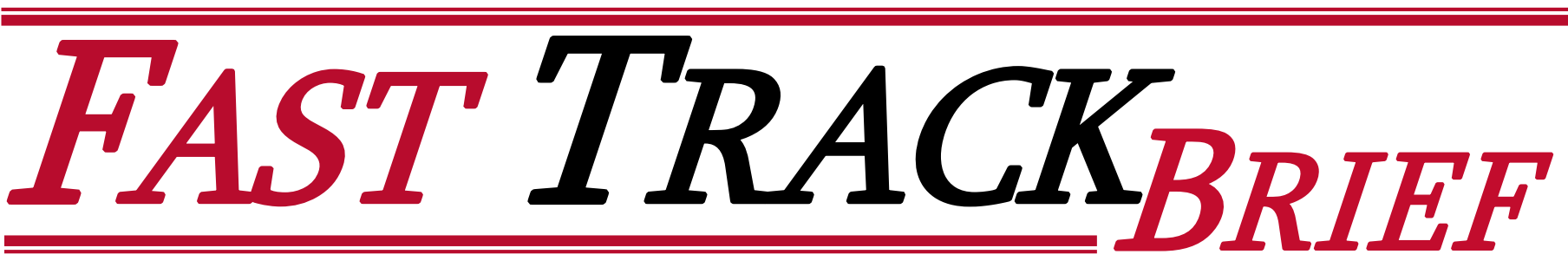

March 9, 2009

The IEG report "Improving Municipal Management for Cities to Succeed," was discussed by CODE on March 9, 2009

\title{
Improving Municipal Management for Cities to Succeed
}

Cities now host half the world's population and provide 70 percent of world GDP. Managing them well is vital for development. The Bank has assisted nearly 3,000 municipalities worldwide over the past decade.

- This Bank assistance has helped strengthen the planning, finance and service provision dimensions of municipal management through 190 operations identified by IEG as municipal development projects (MDPs). Best results for municipalities came through stronger flows of revenues, better financial management, information systems and ability to manage procurement. Weaker results were found in monitoring and evaluation, operations and maintenance, private finance of services and lack of poverty focus.

Wholesale MDPs serving many municipalities had better outcomes than retail MDPs serving just a few. Performance based criteria for municipal participation and greater competition may help explain the stronger wholesale performance, but more in-depth analysis of causal factors is needed.

1 he purpose of this IEG special study is to illuminate the scale and scope of Bank support for municipal development and to draw specific lessons from the achievements and failures of a sample of individual projects. The findings of the study are based on a review of all 190 MDPs completed or ongoing during 1998-2008. In consultation with World Bank operational staff, IEG identified MDPs as projects with objectives and components focused on strengthening municipal management in cities having 12,500 inhabitants or more. Of these $190 \mathrm{MDPs}$, the 114 completed operations are the principal source for the evaluation findings. Ninety MDPs were studied through IEG desk reviews of Implementation Completion Reports (ICRs), and 24 were the subject of detailed IEG field assessments, summarized in Project Performance Assessment Reports (henceforth called PPAR MDPs).
The study focuses on three dimensions of municipal management—planning, finance, and service provision - that figure repeatedly in Bank-financed MDPs. The planning dimension refers to the capacity of a municipality to forecast and oversee its own progress. It includes information systems, monitoring and evaluation (M\&E), city planning, and investment strategies. The finance dimension refers to how a municipality manages the resources needed to provide services to its constituents. It covers financial management, own-resource mobilization, access to credit, and private funding. The service provision dimension refers to the capacity of a municipality to manage the services required by city residents and business people through the effective prioritization of investments, management of competitive procurement, and sustaining of services through operations and maintenance (O\&M). 


\section{Overview of Bank Support for Municipal Management}

From FY1998-2008, the Bank committed \$14.5 billion, 3.4 percent of its total lending, to these 190 MDPs. The projects have assisted nearly 3,000 urban municipalitiesabout 15 percent of all those in developing countries, more than a third of which are in the Latin America and Caribbean Region. The level of MDP support to an individual municipality has varied enormously, from tailormade technical assistance and significant investment funding to training just a few municipal staff. Up to 345 million people-IEG's estimate for the entire population of the 3,000 participating municipalities — might have benefited.

The Bank has supported MDPs in all six operational regions. The largest number has been in Africa (27 percent of the total), and the largest lending commitment has been in East Asia (38 percent of the total). Seventy-four percent of the 114 completed MDPs obtained satisfactory outcomes using IEG criteria, compared with 77 percent for all Bank operations. The strongest regional MDP performers have been Latin America and East Asia, with 86 and 80 percent satisfactory outcomes respectively.

The number of municipal clients assisted by each MDP has varied significantly. "Wholesale MDPs" serving seven or more municipalities occupy the top two quintiles of this distribution. The average wholesale MDP covers 65 municipalities. Wholesale MDPs have been strong performers, with 85 percent having satisfactory outcomes. "Retail MDPs" serving six or fewer municipalities make up the lower three quintiles of the distribution. The average retail MDP serves just three municipalities. These MDPs have been weaker performers, with only 67 percent obtaining satisfactory outcomes.

Although more analysis is needed, several factors may help to explain the stronger performance of wholesale MDPs. First, wholesale MDPs can spread the downside risk of failure broadly across many municipalities. Second, competition among municipalities, a feature of all the wholesale operations reviewed, means both that municipalities that fail to meet MDP performance criteria may no longer be entitled to project support and that weak municipalities that do not qualify at the outset may become eligible for project funding later if their performance improves. Third, the study found that wholesale MDPs allocate a significantly larger share of project spending to technical assistance and institutional development. Fourth, it is possible that municipality size is a factor-for example, if wholesale MDPs deal more with smaller, less complex municipalities, although this could not be tested given the striking absence of population data for the municipalities they serve.

All MDPs in the portfolio of 190 have aimed to strengthen municipal management in one or more of its planning, finance, or service provision dimensions. Surprisingly given its priority in the Bank's urban strategy and the Banksupported Cities Alliance, better planning has been an objective of just one-third of MDPs, the least attention among the three dimensions. Finance has been addressed in MDP objectives more than half the time. Service provision has featured in the objectives of nearly all of them.

Only 27 percent of the 190 MDPs in the portfolio have had project objectives focused on assisting the poor or have indicated how the poor might benefit from stronger municipal management. Earlier IEG evaluations of urban lending found twice that share. The lack of MDP poverty focus is a serious shortcoming, especially given the poverty emphasis in the Bank's urban strategy and new estimates putting the number of poor people in cities at 746 million.

\section{In-Depth Findings from Project Assessments}

In addition to the broad portfolio review summarized above, IEG undertook detailed field-based assessments of the performance of 24 MDPs. These throw light on both successful practices and remaining challenges along the three dimensions of planning, finance, and service delivery.

Better Municipal Planning. Though planning is a priority under the Bank's urban strategy and a tool widely used by municipalities for mapping future city development, it was not a consistent priority in the MDPs (with 17 of the 24 PPAR MDPs focusing on it). Six of the 24 obtained substantial or better results in enhancing municipal information systems, one dimension of planning. A notable success was the establishment and consolidation of Chile's Web-based National System for Municipal Information. In contrast, centralized municipal information systems in Sri Lanka and Mozambique failed, in part because municipalities themselves had restricted access to them. Clearly, municipal involvement in the use of such systems is a factor of success.

Monitoring and evaluation is another aspect of planning. When it worked well, which was rarely-only 4 of the PPAR MDPs had substantial results in this area-it was a hands-on instrument for the day-to-day management of project implementation and for evaluation. The weak performance of the majority often reflected inadequate attention to project results themselves. Even where MDP information systems were good-as they were in Chile, China, and Indonesia-project M\&E in most cases 
measured only the delivery of project components and not the achievement of an operation's objectives (such as reaching the poor in Brazil's MDP in Ceara). M\&E generally worked better when using more widely available municipal finance data, as it did in Tunisia and Colombia. A very strong M\&E system was built into Russia's MDP in Kazan, where some M\&E performance indicators doubled as tranche release conditions, enhancing the status and importance of the M\&E itself. Moreover, Kazan municipality saw the usefulness of M\&E for its own planning, and not just for fulfilling a Bank project requirement.

Relatively few MDPs attempted to strengthen city planning. Eight cases yielded substantial results, while two MDPs performed poorly. Among the successes, retail MDPs in China helped the cities of Ningbo and Tianjin develop city planning in a way that served as a model for the whole country. Sri Lanka's MDP enabled the capital Colombo to update its master plan, as Zimbabwe's did for the small city of Victoria Falls. Wholesale MDPs in Chile, Colombia, and Tunisia brought city planning to many smaller municipalities for the first time. Weaker results came in Indonesia, where municipalities reacted coolly to the complex model of integrated planning proposed by one MDP and expressed little demand for city planning in another. Notably absent was the City Development Strategy, an instrument intensely promoted by the Cities Alliance yet rarely supported in MDPs.

Municipal (non-spatial) investment strategies made headway in five PPAR MDPs. Projects in Chile, China, India, Russia, and Tunisia enabled municipalities to become more "business friendly," and two MDP clients in China rose to the top of a nationwide list of municipalities with the best investment climate in the country.

\section{Stronger Municipal Finances. Most PPAR MDPs} addressed the financial dimension of municipal management, in which the study found more good results than in the planning and service provision dimensions.

Half of these PPAR MDPs had substantial results in financial management. Good results came through project technical assistance and on-the-job learning that enabled many small municipalities in Chile, Georgia, the Gambia, India, and Tanzania to adopt computerized accounting and financial systems for the first time. Larger municipalitiessuch as Kazan, Maputo, and Tianjin—unified accounts and integrated financial management across their large organizations. Among the 4 less successful MDPs, Georgia and Uzbekistan were hindered by weak municipal capacity before the project.

Again, half the PPAR MDPs achieved substantial results in enhancing revenue mobilization. These successful MDPs updated tax records, expanded the coverage of cadastres or land registers, and enhanced collections. Municipalities receiving such support in Brazil and Colombia saw their own revenues increase faster than fiscal transfers.

Participant municipalities in Georgia saw significant growth of own revenues that had fallen for nonparticipants over the 2002-05 period, and own revenues of participating municipalities in the Gambia grew 50 percent faster than expected. Weaker results for eight MDPs in Brazil, Indonesia, Mozambique, and Zimbabwe arose from political reluctance by some municipalities to raise taxes.

Improvement of municipal access to credit was an infrequent priority, with only six PPAR MDPs focusing on it at all. Of these, five had substantial efficacy in helping to "bring municipalities to market." MDPs in Colombia were particularly successful in establishing a local credit market, complete with recognized credit ratings of active municipalities, some becoming able to issue municipal bonds for the first time. Municipalities learned about prudent debt management through wholesale MDPs in Brazil, India, and to a lesser degree Georgia.

Stimulating private finance of municipal services was an objective in only five MDPs, and only one (in Colombia) yielded substantive results through private funding of water, gas, and solid waste services in several municipalities. Many municipalities lack the expertise to staff the contract management units needed to engage the private sector. The less successful MDPs promoted privatization of solid waste operations in Sri Lanka and Uzbekistan that did not go far given poor financial performance and uncertain regulatory environments. In Zimbabwe, funding of low-income municipal housing was not forthcoming from private building societies and their higher-income product lines. These weak results might have been averted with more accurate assessments of local financial markets and the demand for municipal services that could ensure the potential profitability of private funding.

Managing Service Provision. Management of municipal service provision was a priority in all 24 PPAR MDPs. In prioritizing investments in services, however, only 7 MDPs successfully supported the clients' application of costbenefit analysis with estimates of economic rates of return (ERRs). Simple yet robust estimates of ERR were made for MDPs in China, Ghana, India, Indonesia, Tanzania, and Zimbabwe. They included accurate cost figures and realistic assessments of future benefits, often measured by the increased value of serviced land. Good M\&E systems helped produce some of the data needed for ERRs. In all cases, municipalities themselves were involved in the analyses. Given its successful application in cases such as these, why were ERR estimates used so little by MDPs? Among the reasons given: high cost, lack of data, and externalities. But simple methods that make full use of existing data can help overcome these constraints. 
Nine MDPs led to substantial strengthening of procurement management at the municipal level, and some other MDPs dealt with municipalities that were already familiar with handling their own procurement and needed little project support. Where municipalities handled procurement, local beneficiaries were better informed about the service improvements provided. Even larger municipalities, such as Kazan, Tashkent, and Tianjin, were introduced to more complex procurement packages, including international competitive bidding, by their respective MDPs.

Few MDPs had substantial results in strengthening the municipal management of operations and maintenance $(\mathrm{O} \& M)$, which is necessary to ensure ongoing service provision. The few successful cases were in Africa, where MDPs helped computerize municipal maintenance in Tanzania and establish and fund municipal O\&M accounts in the Gambia. Other successes were evident in Ghana and Tunisia. On the other hand, lack of adequate O\&M in MDPs led to service failures in Georgia, Indonesia, and Zimbabwe. These cases show that the risk to development outcomes can increase significantly if O\&M is neglected.

Only MDPs in Brazil, the Gambia, Ghana, and Tanzania had objectives that explicitly addressed poverty alleviation or service access by the poor. Visual inspections of these projects during field missions confirmed there were poor beneficiaries, although there was little data on specific poverty impacts. Evidence elsewhere was even thinner due to a lack of poverty focus and monitoring. The Bank still has much work to do to address its poverty reduction mission through partner municipalities. Being able to define poverty-related objectives and measure actual results of MDPs for the poor would make an important contribution.

\section{Lessons}

Several forward-looking lessons arise from the findings of this study that are relevant for future operations and the broader municipal management agenda:

- Among the three dimensions of municipal management—planning, finance, and service provision-MDP support for strengthening municipal finance most often yielded successful results according to field assessments. The Bank
INDEPENDENT EVALUATION GROUP

should continue to support the tightening of municipal financial management, raising of municipal own revenues, and bringing of municipalities to local credit markets when appropriate conditions are present.

- Project documentation that routinely reports basic data about each client (municipality name, population, and MDP investment) is vital to developing a better understanding of the scope of MDP results.

- Wholesale MDPs that have assisted many municipalities have yielded better outcomes than retail MDPs over the past decade, but more analysis is needed to understand the precise reasons for the performance differential. Retail MDPs might perform better if they incorporated more of the winning elements of wholesale MDPs, such as performance-based incentives and a focus on finance.

- More frequent use of cost-benefit or cost effectiveness analysis would help MDPs' municipal clients select the best investments and achieve outcomes efficiently. IEG found that only half of MDPs do this, with the best coverage in the Africa Region.

- For M\&E to succeed in MDPs, it has to be useful and not unduly burdensome to municipalities themselves, while keeping a focus on achieving results, particularly for the poor. Strong M\&E can also help reduce the expense of cost-benefit analysis by providing some of the data needed to estimate ERRs. Few MDPs have succeeded with this.

- Private finance of municipal services can be encouraged through better analysis of local financial markets and deeper understanding of demand to help municipalities gain the trust of private investors.

- Thus far, little evidence exists that stronger municipal management has benefited the poor. MDPs need to give much more attention to poverty reduction in defining MDP objectives, showing how the poor would benefit from municipal investments and services improved through stronger municipal management. 


\footnotetext{
About Fast Track Briefs

Fast Track Briefs help inform the World Bank Group (WBG) managers and staff about new evaluation findings and recommendations. The views expressed here are those of IEG and should not be attributed to the WBG or its affiliated organizations. Management's Response to IEG is included in the published IEG report. The findings here do not support any general inferences beyond the scope of the evaluation, including any inferences about the WBG's past, current or prospective overall performance.

\section{***}

The Fast Track Brief, which summarizes major IEG evaluations, will be distributed to selected World Bank Group staff. If you would like to be added to the subscription list, please email us atieg@worldbank.org,with "FTB subscription" in the subject line and your mail-stop number. If you would like to stop receiving FTBs, please email us at ieg@worldbank.org,with "FTB unsubscribe" in the subject line.
}

\section{Contact IEG:}

Director-General, Evaluation: Vinod Thomas Director: Cheryl Gray (IEG-WB)

Manager: Monika Huppi (IEGSE)

Task Manager: Roy Gilbert (IEGSE)

Copies of the report are available at:

http:/ /www.worldbank.org/ieg/

IEG Help Desk: (202) 458-4497

E-mail: ieg@worldbank.org 